NBSIR 73-138

\section{TIME SERIES FORECASTING OF HIGHWAY} ACCIDENT FATALITIES

Alexander R. Craw

Institute for Applied Technology

Technical Analysis Division

National Bureau of Standards

Washington, D. C. 20234

March 1973

Final Report

Prepared for

National Highway Traffic Safety Administration

Department of Transportation

Washington, D. C. 20590

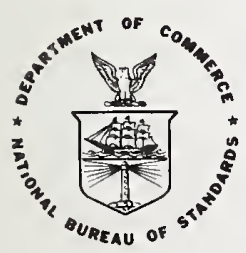

U. S. DEPARTMENT OF COMMERCE, Frederick B. Dent, Secretary

NATIONAL BUREAU OF STANDARDS, Richard W. Roberts, Director 



\section{ACKNOWLEDGEMENT}

Particular thanks are due to Mrs. E. Leyendecker, who ran all of the computer programs and carried most of the computational analysis load. Also, to Dr. Julius Lieblein for many helpful suggestions and for discussions that provided insight into what had often been obscure. 

SUMMARY SUMMARY $\cdot \cdot \cdot \cdot \cdot \cdot \cdot \cdot \cdot \cdot \cdot \cdot \cdot \cdot \cdot \cdot \cdot \cdot \cdot \cdot \cdot$. $\cdot$.

1.0 THE PROBLEM . . . . . . . . . . . . 1

2.0 THE DATA AND AUXILIARY INFORMATION AVAILABLE. . 1

3.0 REAdILy AVAILABLE COMPUTER PROGRAMS . . . . . 2

4.0 PLAN OF ANALYSIS. . . . . . . . . . . . 2

5.0 PRODUCTION RUNS . . . . . . . . . . . . 3

6.0 CONCLUSIONS . . . . . . . . . . . . 8

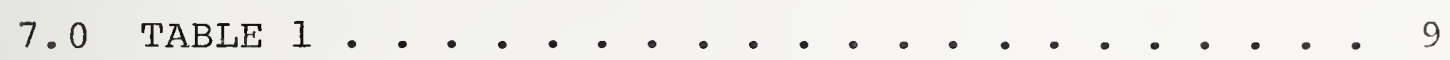

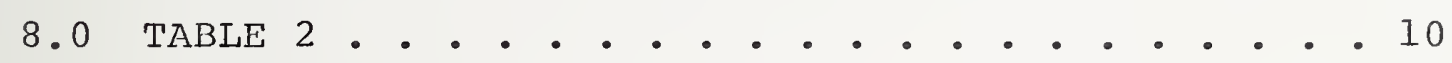

9.0 TABLE 3 . . . . . . . . . . . . . . 11

10.0 TABLE 4 . . . . . . . . . . . . 12

11.0 TABLE 5................ . . 13

12.0 TABLE 6 . . . . . . . . . . . . 14

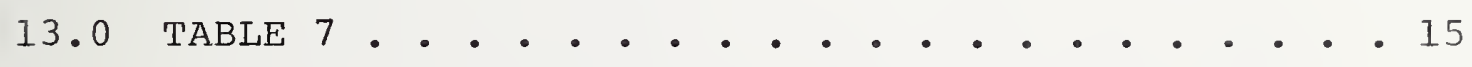

14.0 TABLE 8 . . . . . . . . . . . . . 16

15.0 TABLE 9................. . . 17

16.0 APPENDIX A, EXPONENTIAL METHODS FOR

ANALYSIS AND FORECASTING OF ECONOMIC TIME SERIES . . . . . . . . . . . . . . A-I

17.0 APPENDIX B, AVAILABLE COMPUTER PROGRAMS AT NBS FOR TIME SERIES ANALYSIS . • . . . . . B-I

18.0 APPENDIX C, DETAILS OF EXPSMOOTHING ROUTINE: . . - 1 

Using twelve years of time series data on highway fatalitics, the methodology currently employed by the National Highway Traffic Safety Administration (NHTSA) to forecast the annual (calendar year) total of highway accident fatalities were compared with those obtained by several computer routines based on exponential smoothing techniques and available at the National Bureau of Standards. The use of unadjusted and seasonally adjusted data was also examined.

It is found that there is no coercive evidence to lead to abandoning the present NHTSA methods in favor of readily available computer routines based on exponential smoothing methods.

of the methods examined in this study, the best results were obtained with the EXPSMOOTHING routine using unadjusted fatality data. 

1. The Problem: The Technical Analysis Division has been requested to examine the National Highway Traffic Safety Administration's (NHTSA) current methodologies for forecasting the annual total of highway accident fatalities given the monthly fatalities respectively for the first three months of the year, the first six months and finally the first nine months of the year, make comparisons of the results of their methodologies with those based on readily available computer programs at the National Bureau of Stanảarảs for time series analysis and forecasting.

\section{The Data and Auxiliary Information Available:}

Data for each month are available for the twelve (12) year period 1960 through 1971. Also available are the outputs of NHTSA's Computer Program TIMSR4: Time Series Analysis of Fatalities and Vehicle-mileage Data. This time series analysis program provides $12-$ month moving averages, monthly seasonal indices, seasonally adjusted data for each month and the ordered differences between the seasonally adjusted data ana an uncentered twelve month moving average. The ordered differences are used to determine for any month of a time series upper and lower bounds for the trend point such that the seasonally adjusted value will fall within those limits with a known frequency.

The TIMSR4 Program does not have an automatic extrapolation (forecasting ahead) feature. The NETSA Methods of forecasting that we were asked to review are discussed in Section 5. 
3. Readily Available Computer Programs: A constraint imposed on the study was to use computer programs that were readily available at the National Bureau of Standards. Thus, a comprehensive study of methods is not given here.

Several time-sharing interactive systems were immediately available. These were DIALCOM, Computer Sciences Corporation Conversational Executive and General Electric Mark II. Of these time-sharing programs we chose to use the General Electric EXPSMOOTHING routine, because of the variety of options available and the existence of an automatic extrapolation feature.

The Large Scale Systems STAT-PACK for the UNIVAC 1108 lists several routines for time series analysis. These are UNIVAC system subroutines and are not necessarily National Bureau of Standaras routines, but they are available for use on the NBS UNIVAC 1108. The most appropriate subroutine for the problem at hand appeared to be GEXSMO - Generalized Exponential Smoothing.

Appendix $B$ contains a discussion of the available computer programs at NBS as well as a discussion of the back:ground and details of the GEXSMO computer program. Appcndices $A$ and $C$ provide the same information for the EXPSMOOTHING program.

4. Plan of Analysis:

a. Use the General Electric - EXPSMOOTfING routile and the UNIVAC STAT-PACK GEXSMO routine. 
b. Use both seasonally adjusted data and scasonal factors (as determined by the TIMSR4 program) and unadjusted data in separate runs.

c. Base forecasts on $4,6,8$, and 11 years of data plus data for 3,6 , and 9 months of new data.

d. Do c. for each of the NHTSA forecasting algorithms.

5. Production Runs: We started production runs using the General Electric Time-share routine EXPSMOOTHING, using seasonally adjusted data that was determined by NHTSA's TIMSR4 computer program. We always chose the most complete output option, so that the routine always performed a cyclic analysis: if a cycle was indicated by the routine, the analysis part of the program took this into account. (We view this as a not too interesting bonus of the routine.) Horizon time was always chosen to exceed the lead time.* The statistical analysis of the output was accomplished by a mixture of computer and hand calculations. The results of this group of calculations are contained in Table 1.

The total amount of data available for forecasting covered 11 years, with a minimum of 3 years of data considered

*In the ExPSMOOTHING Program, the lead time is the term used to describe the time (in periods) between the last period of data one has as data as input and the period one is most interested in estimating correctly. The forecast will be optimized according to the lead time that is entered. The forecast horizon indicates how many periods beyond the last data point that will be forecasted, but has nothing to do with the optimization. (See Appendix A). 
necessary for suitable application of the exponential smoothing process. Thus, annual "forecasts" could be made after 3, 6, and 9 months in each of 8 years. Instead of analyzing this full set of 24 * periods, half of thesc were chosen, namely the three periods in those years with $4,6,8$, and 11 antecedent years of data.

In the headings of Table 1, and subsequent tables, the following symbols were adopted:

$S=$ the actual value of the time series datum (in this case, fatalities)

$\hat{\mathrm{S}}=$ an estimate of $\mathrm{S}$

$\tilde{\mathrm{S}}=$ seasonally adjusted value of $\mathrm{S}$ $\Delta=\hat{S}-S ;$ if $\{\Delta>0\}$ the estimate is above $\}$ the

$\Sigma=$ summation over the lead time

$\Sigma^{*}=$ summation over the calendar year (Jan. - Dec.)

$\Sigma \Delta / \Sigma S=$ (signed) fractional error over lead time

$\Sigma^{*} \Delta / \Sigma^{*}=$ (signed) fractional error over the calendar year (Jan. - Dec.)

MAD = mean absolute deviation

$\alpha=$ smoothing constant

$\mathrm{k}=$ length of cycle; $\mathrm{k}=1$ indicated data is not cyclic.

One of the interesting features of Table 1 is

that thore is no apparent pattern for the cycles with the age of the data. The same holds true for the a value (smoothin constant) and the order of smoothing. This led us to dupli-

* An additional 3 periods were analyzed for noncalendar twelve-month years, raising the potential sample size to 27 and the number tested to 15 . 
cate these computations by suppressing the cyclic analysis. The summary of the results of these computer runs is given in Table 2. Here there does appear to be some reasonableness in the variation of the smoothing constant with data age. The comparison of the forecasting results (Table 3 ) shows a slight advantage to the case of using the cyclic analysis, but the results are not heavily in favor of the latter. In the case of 4 years and 3 months of seasonally adjusted data, the computer routine selected $\alpha=0.175$ (order 2) for the optimum smoothing constant. We were interested in determing whether or not the minimum was sharp or flat, so we made runs for $\alpha=0.170$ and 0.180 . The order of smoothing remained at 2 and the minimum was fourd to be flat; only a very slight change in forecast error fraction could be gained by changing a from .175 to .170 (see Table 4). The change is from 0.0121 to 0.0109 .

Table 5 presents the results of duplicate runs using unadjusted data in the EXPSMOOTHING routine. Cyclic analysis was permitted and each time the routine selected $K=12$ for the dominant cycle.

We also made matching runs starting with unadjusted data on the UINIVAC 1108 program GEXSMO, starting with a given cycle (seasonality) length of 12 and using 2 initial periods to determine the initial seasonality factors and other starting values. The GEXSMO routine always produces a forecast for the time indicated as the length of the cycle 
starting from the last input datum. In the language of the EXPSMOOTHING routine, the lead time is 1 and the horizon time is the length of the cycle. The summary statistics for these runs are presented in Table 6 .

It is interesting to note that in working with unadjustec data and these two computer routines, it is possible to compare the seasonally adjusted data and seasonality factors produced by these routines with those determined Wy the TIMSR 4 program. We have not made these comparisons, preferring at this stage to look at the end results.

Table 7 presents the detailed calculations for the current methodologies employed by NHTSA to forecast the calendar year fatalities. These methods were developed in accordance with descriptions furnished by Mr. Donald F. Mela in his letter of November 30,1972 , and have been labelled 1,2 and 3 in the same order as described by Mr. Mela. Figher order methods are possible by taking into account more years of input data in the averaging process, but we have limited ourselves to the first three methods. The notations used in the column headings of Table 7 are:

$$
\begin{aligned}
& m_{0}=\text { current total for specified months of fatalities } \\
& m_{-i}=\text { the corresponding total for specified months of } \\
& \text { fatalities for ith previous year. }
\end{aligned}
$$


$Y_{-i}=$ the total fatalities for the $i$ th previous year

$\lambda=$ Leap year adjustment factor

$\hat{Y}_{j}=$ the forecast calendar year fatalitics $\mathrm{b}_{Y}^{\prime}$ method $j$

With this notation the NHTSA forecast methods may be written:

Method 1: $\hat{Y}_{1}=\left(m_{0} / m_{-1}\right) Y_{-1}$,

Mothod 2: $\quad \hat{Y}_{2}=\lambda \hat{Y}_{1}$

Method $3: \quad \hat{Y}_{3}=\lambda\left(i n_{0} / \sum_{1}^{3} m_{-i}\right) \sum_{1}^{3} Y_{-i}$

$\operatorname{Method~} \mathrm{k}: \hat{\mathrm{Y}}_{\mathrm{k}}=\lambda\left(\mathrm{m}_{\mathrm{O}} / \sum_{1}^{k} \mathrm{~m}_{-i}\right) \sum_{1}^{\mathrm{k}} \mathrm{Y}_{-i}, \mathrm{k}>1$

Table 8 presents a composite summary of the fractional errors by each of the methods considered. In this table and Table 9, SAC = Seasonally adjusted data with cyclic analysis.

Considering just the NHTSA's methods, we find a gradual improvement in the forecast with increasing order of the method. However, in certain specific cases Method 2 gives slightly better results with methods of order greater than 2. Generally, the error decreases with the shorter lead time.

Comparing the four exponential smoothing methods, the sample evidence seems to favor EXPSMOOTHING using unaajusted data. However, each of the four methods has a mean absolute deviation of approximately 1 percent, which is virtually indistinguishable from that of Method 3. 
Comparing the "best" NHTSA method (Method 3) with the "best" exponential smoothing routine we find for the sample of 12 trials out of the possible 24 forecasts that method 3 was better 5 times and the best exponential smoothing method was better on 7 occasions. This is obtained by comparing the entries in columns headed $\Sigma^{*} \Delta / \Sigma^{*} S$ and Unadj $C$ in Table 8. However, the range of the absolute deviations of the exponential methods is smaller than that of any of the methods 1, 2 or 3 . Thus, it would appear that there is a small gain in going to the exponential smoothing methods.

Our experience in using the EXPSMOOTHING routine has made us wary of using long lead times, in particular $\mathrm{L}=12$. In some cases we have found that better results can be obtained in making forecasts for a year ahead by using $L=3$ in place of 12. See Table 9 for the appropriate comparisons. However, no clear cut rule can be recommended. 6. Conclusions

For the forecasting problem at hand (see section 1), if one can live with the percentage range of errors indicated with the present NHTSA's methods, there is no coercive evidence to lead to abandoning the present methods in favor of readily available computer routines for exponential smoothing methods.

of the methods examined in this study, the best results were obtained with the ExPSMOOTHING routine using unadjusted fatality data. 


\begin{tabular}{|c|c|c|c|c|c|}
\hline O & $\mid \begin{array}{l}x \\
x \\
0 \\
8\end{array}$ & 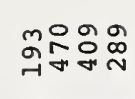 & बूल $\stackrel{n}{\sim} \underset{n}{n}$ & 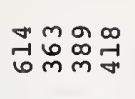 & 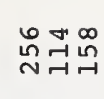 \\
\hline & $\sum_{\omega}^{20}$ & 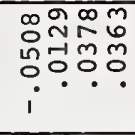 & 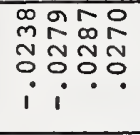 & 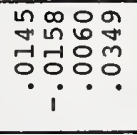 & 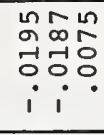 \\
\hline & rw & 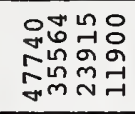 & 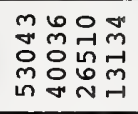 & 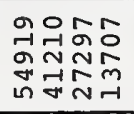 & 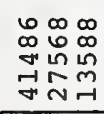 \\
\hline & एव & 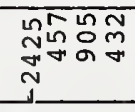 & 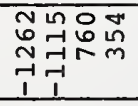 & 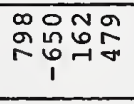 & $\begin{array}{lll}0 & 0 & 0 \\
0 & 0 & 0 \\
0 & 1 & 0 \\
1 & 1 & -1 \\
1 & 1\end{array}$ \\
\hline & 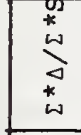 & 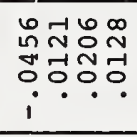 & 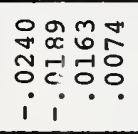 & 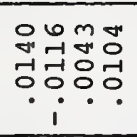 & 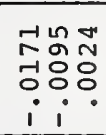 \\
\hline & $\sum_{\omega}^{\infty}$ & 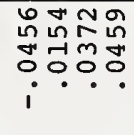 & 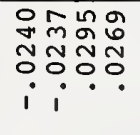 & 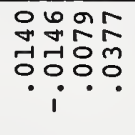 & 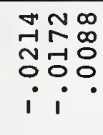 \\
\hline & $\begin{array}{l}\omega \\
* \\
\omega\end{array}$ & 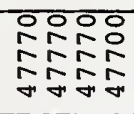 & 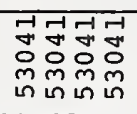 & 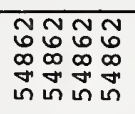 & 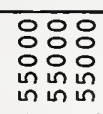 \\
\hline & W & 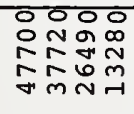 & 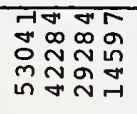 & 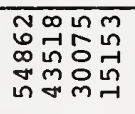 & 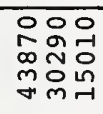 \\
\hline & $\stackrel{\star}{\omega}$ & 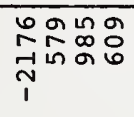 & 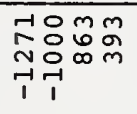 & $\stackrel{\circ}{R} \underset{\sim}{n}{ }_{1}^{\infty} \underset{N}{N} \underset{N}{N}$ & 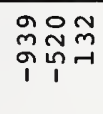 \\
\hline $\begin{array}{l}\mu \\
0 \\
\text { G }\end{array}$ & 㫕 & 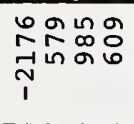 & 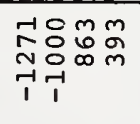 & 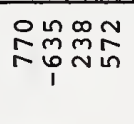 & $\begin{array}{l}\text { 옹요 } \\
\text { o ำ } \\
11\end{array}$ \\
\hline $\begin{array}{l}0 \\
0 \\
0 \\
1 \\
\lambda\end{array}$ & 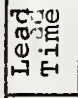 & $\underset{r}{N} \cap 0 \mathrm{~m}$ & $\underset{\sim}{\sim} \sigma 6 \mathrm{~m}$ & $\underset{r}{\sim} \sigma 6 \mathrm{~m}$ & $96 \mathrm{~m}$ \\
\hline 敢 & 景 & 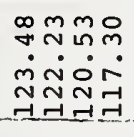 & 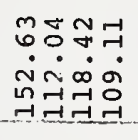 & 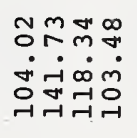 & 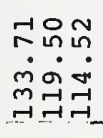 \\
\hline$\underset{\ddot{u}}{\pi}$ & "ृ & $N \sim N N$ & $N \sim N n$ & N & Nનન \\
\hline 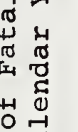 & $\gamma$. & 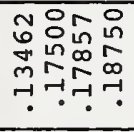 & 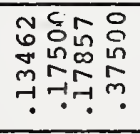 & 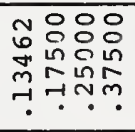 & 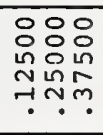 \\
\hline 0 & 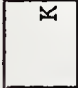 & ঋननન & निन्न & mañ & 유융ㅇ \\
\hline & $\begin{array}{c}0 \\
-1 \\
-1 \\
0 \\
0 \\
0\end{array}$ & Uzzz & UUU & UUU & $0 \cup 0$ \\
\hline 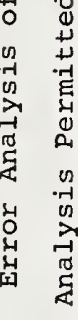 & 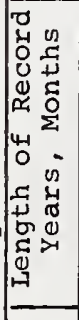 & 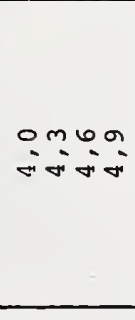 & ตัต & 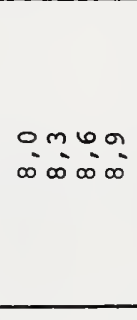 & 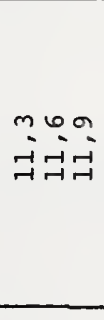 \\
\hline $\begin{array}{c}u \\
-7 \\
0 \\
0 \\
ن\end{array}$ & 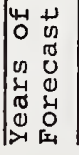 & 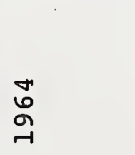 & $\begin{array}{l}0 \\
0 \\
\sigma \\
\end{array}$ & $\begin{array}{l}\infty \\
0 \\
0 \\
\sigma\end{array}$ & r. \\
\hline
\end{tabular}




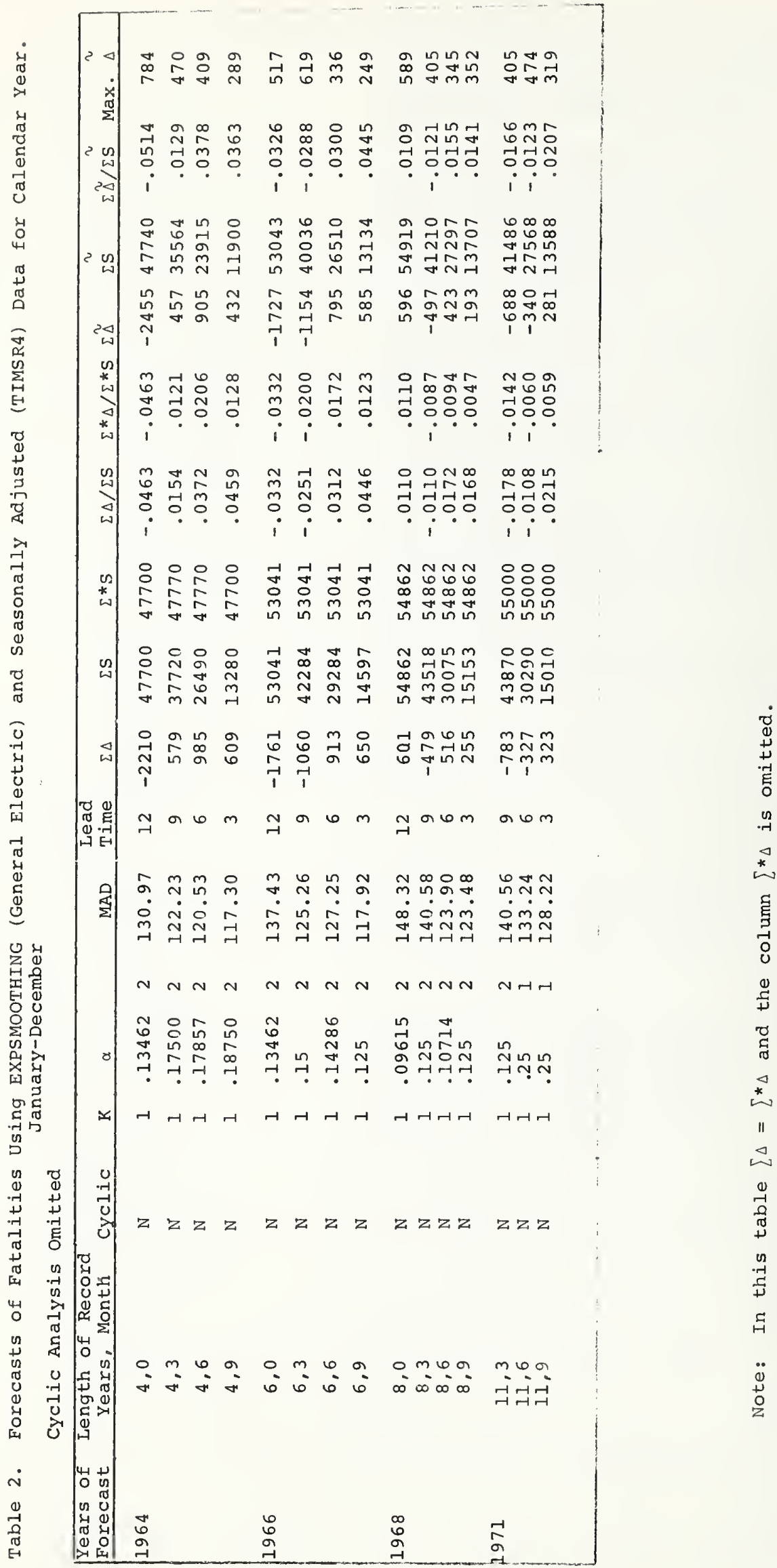




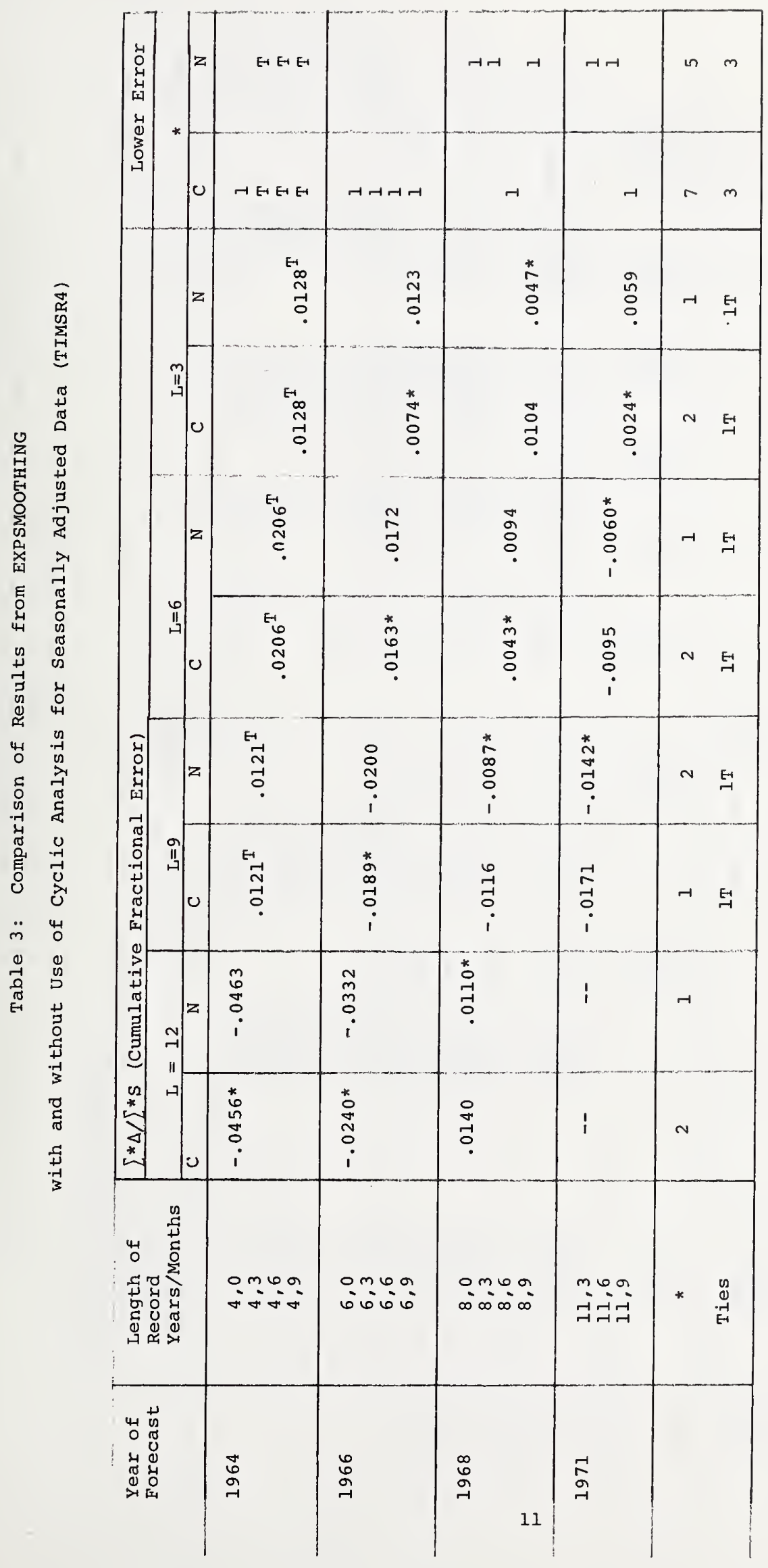




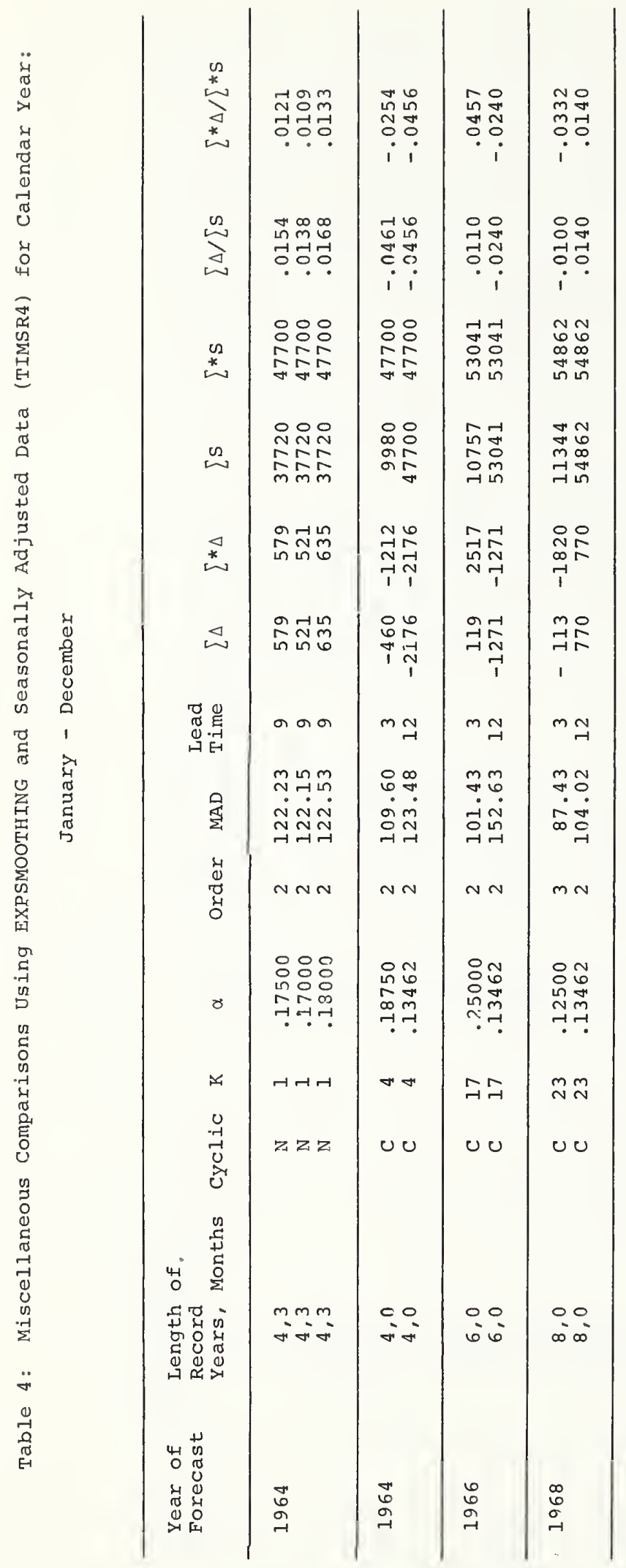




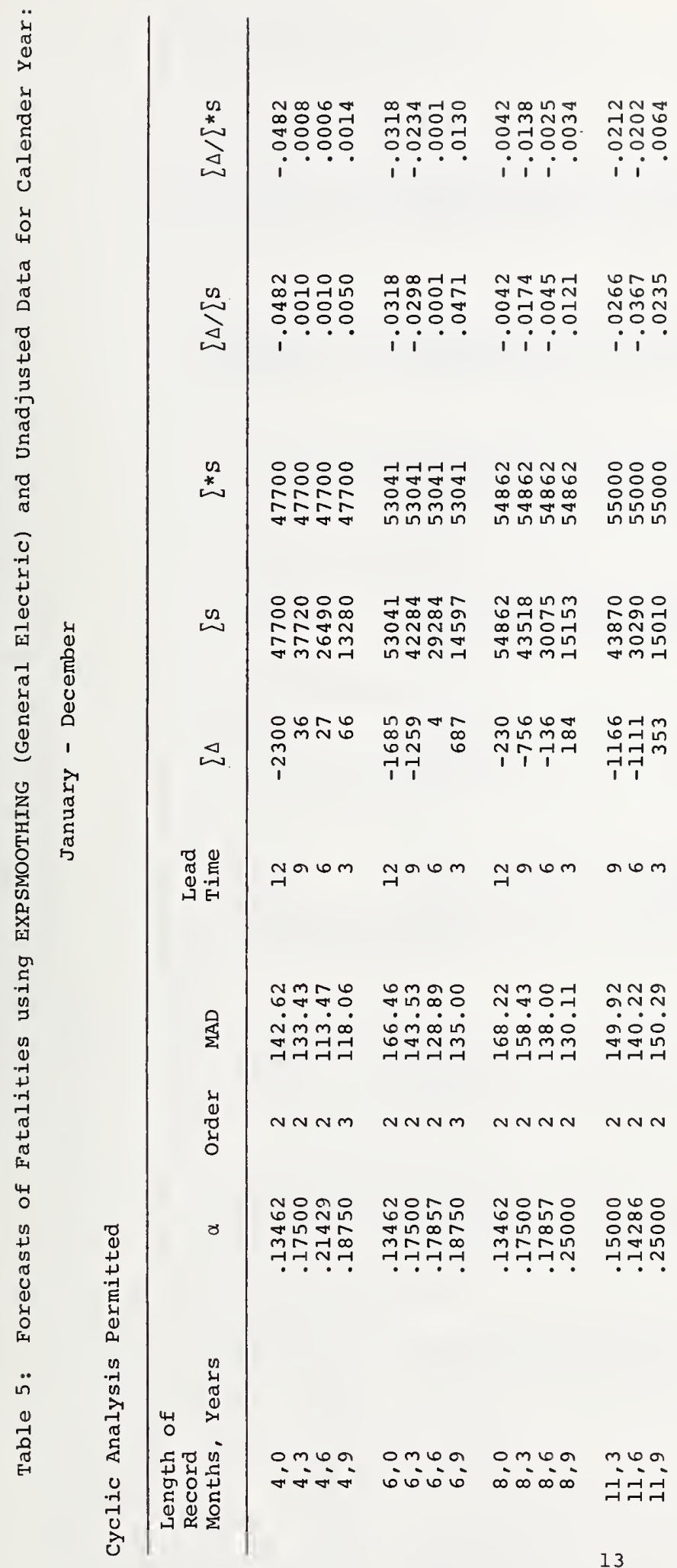




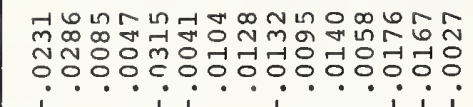

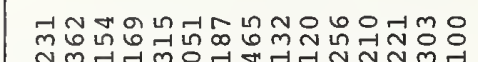

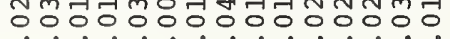
$i \cdot i_{i} i \cdots$

$\operatorname{nin} \pi$

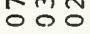

$i i$

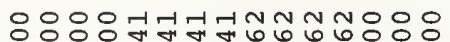

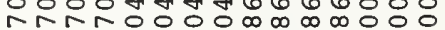

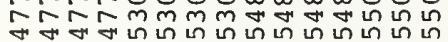

$\begin{array}{lll}1 & 1 & 1 \\ 1 & 1 & 1\end{array}$

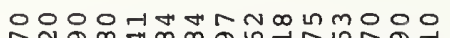

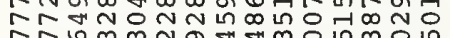

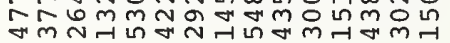

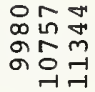

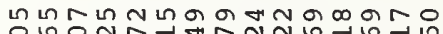

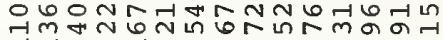

$\overrightarrow{1}+++\overrightarrow{1} 1++1+++11$

귀ำ $\stackrel{\infty}{n}$

111

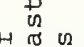

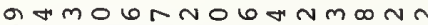

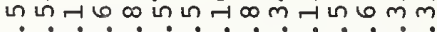

on

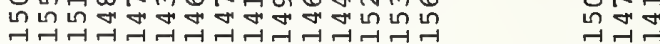

in 0

둘

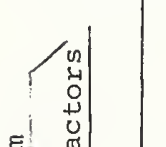

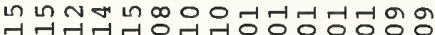

는돈

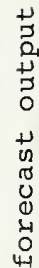

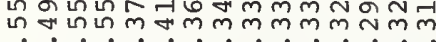

ก้กติก

………

ก

․․ำ.

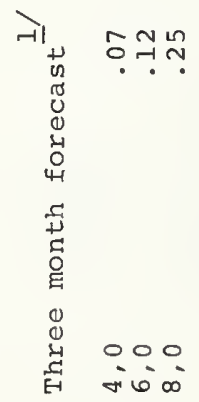




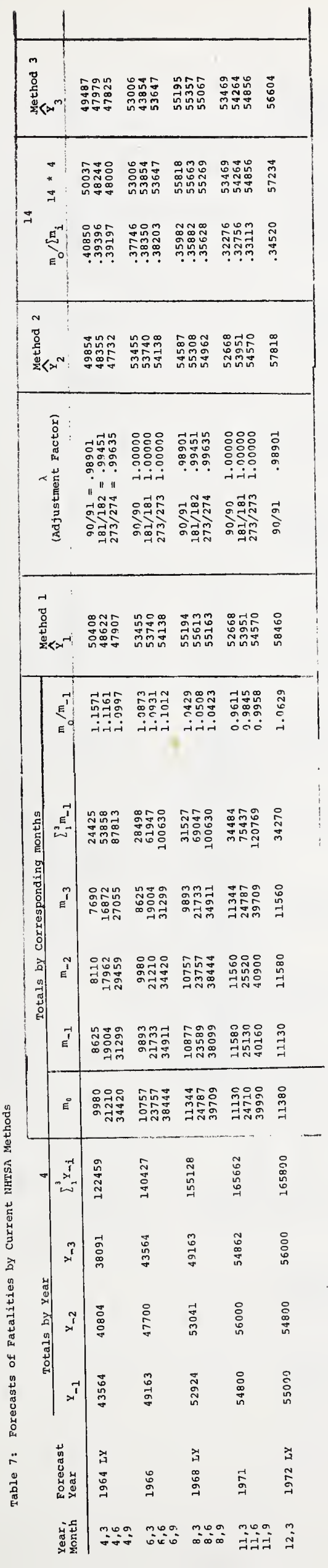




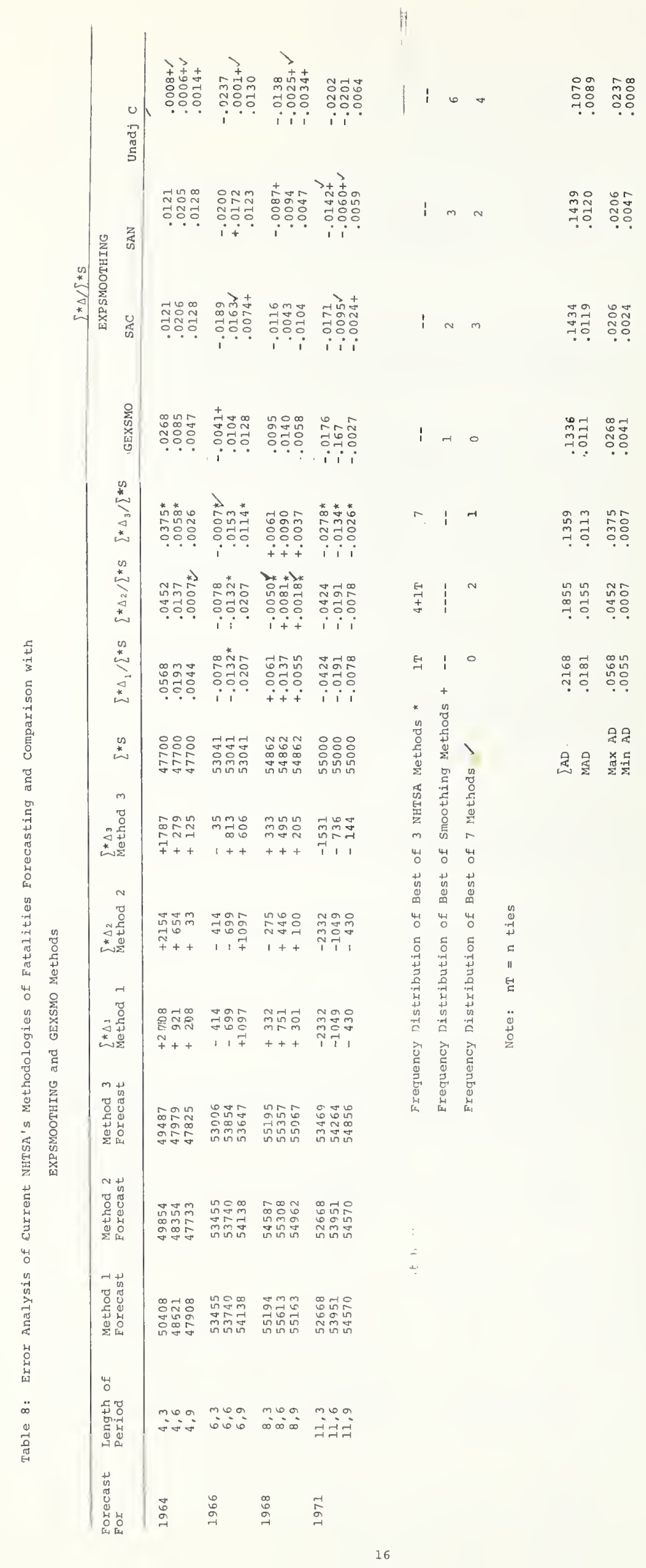




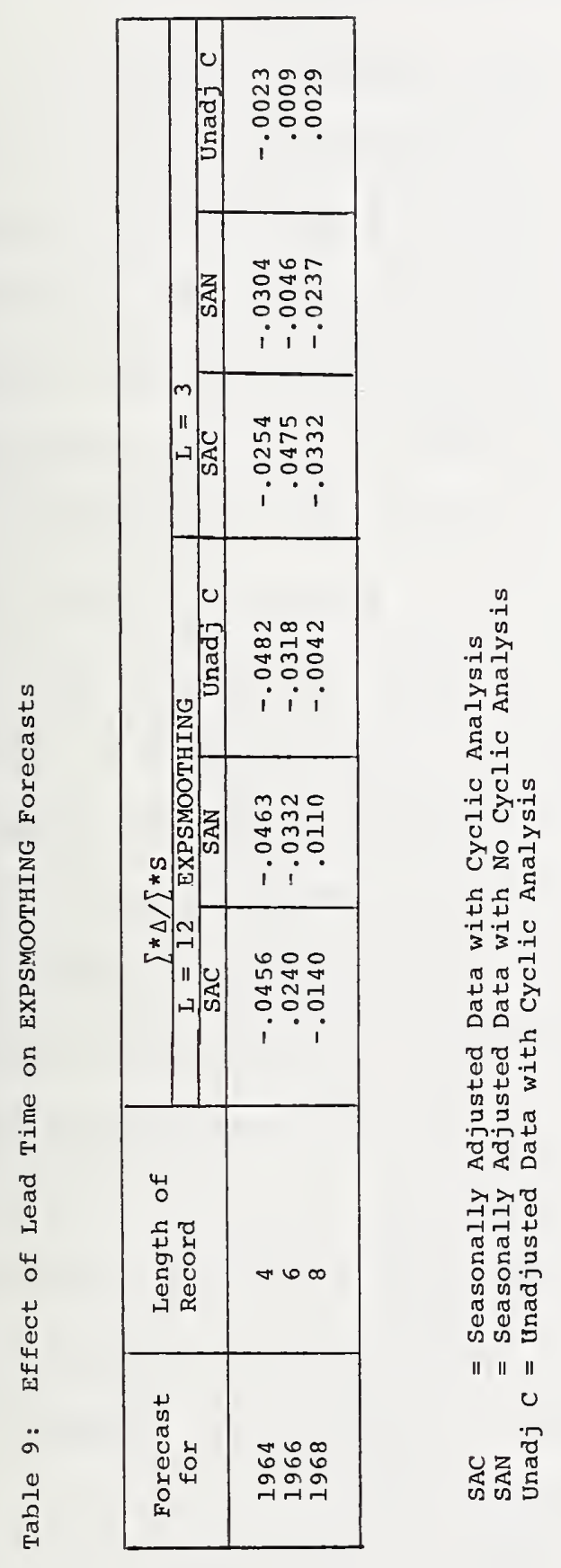





\section{Exponential Methods for Analysis and Forecasting of Economic Time Series}

From approximately 1960, most methods of time series smoothing analysis have gone toward the use of varying weights based on the age of the data. The simple moving average ignores data beyond a certain age and weights equally each datum that is used. The most popular weighting schemes in vogue today are based on some form of "exponential" smoothing. These schemes use all of the data, with the weight given an individual datum decreasing with increasing age of the datum. The rate of decreasing weight is determined by a parameter called a smoothing constant and most frequently denoted by the Greek letter alpha $(\alpha)$. Depending on the nature of the time series, a variety of models may be used to represent the time series, for example, a constant process model $\xi_{t}=a_{0}$ ' a linear process model $\xi_{t}=a_{0}+a_{1} t$, a quadratic process model $\xi(t)=a_{0}+a_{1} t+a_{2} t^{2}$, etc. In each case there is a process $\xi(t)=\sum_{i=0}^{n} a_{i} t^{i} / i$ : which is observed in the presence of noise $x(t)=\xi(t)+\varepsilon(t)$. The number of "degrees of freedom" of these models are respectively $1,2,3$, etc., and this number is sometimes referred to as the order of the model. Multiple Smoothing: If a constant model $\left(\xi_{t}=a\right)$ is used to represent the time series $x(t)=\xi(t)+\varepsilon(t)$, 
"xponential smoothing for estimating the single coefficient in a constant model is

$$
\hat{a}_{t}=s_{t}(x)=\alpha x_{t}+(1-\alpha) s_{t-1}(x)
$$

For estimating the two coefficients in a linear model, the notion of double smoothing is used. For generality the exponential smoothing for the constant model is called single smoothing and is represented by $S_{t}^{[1]}(x), i . e ., S_{t}^{[1]}(x)=S_{t}(x)$. Then double smoothing is defined as $S_{t}^{[2]}(x)=S_{t}^{[1]}(x)+(1-\alpha) S_{t-1}^{[2]}(x)$, Similarly, multiple smoothing of order $\mathrm{k}$ is defined by $S_{t}^{[k]}(x)=\alpha S_{t}^{[k-1]}(x)+(1-\alpha) S_{t-1}^{[k]}(x)$, i.e., $k$ th - order smoothing is just simple exponential smoothing applied to the results of $(k-1)$ st - order smoothing of the data.

As an example, in the case of a linear model:

$$
\xi_{t}=a_{0}+a_{1} t
$$

the forecast of the value of the time series $\tau$ units after time $\mathrm{T}$ is given by

$$
\hat{\mathrm{x}}_{\tau}(T)=\hat{\mathrm{a}}_{0}(T)+\tau \hat{\mathrm{a}}_{1}
$$

where $\hat{a}_{0}(T)$ and $\hat{a}_{1}(T)$ are given by

$$
\begin{aligned}
& \hat{a}_{O}(T)=2 S_{T}(x)-S_{T}^{[2]}(x) \\
& \hat{a}_{I}(T)=\frac{\alpha}{I-\alpha}\left[S_{T}(x)-S_{T}[2](x)\right]
\end{aligned}
$$


A convenient, comprehensive basic reference is R.G. Brown, Smoothing, Forecasting, and prediction of Discrete Time Series, Prentice-Hall, 1963. A summary of the fundamental formulas of multiple smoothing and forecasting are given on pages 142-144, and pages $184 \mathrm{ff}$ of this reference.

We remark at this time that in using multiple smoothing methods two problems arise: (a) what order of smoothing should be used? (b) what value of the smoothing constant should be employed? A third, but minor, problem is the determination of starting values. The mathematical basis for the EXPSMOOTHING computer program is founded on the concepts of multiple smoothing, and utilizes the formulas presented in Brown's book.

A similar but different approach forms the basis of the UNIVAC GEXSMO program. This generalized exponential smoothing program is based on the work of P.R. Winters, "Forecasting Sales by Exponentially Weighted Moving Averages," Management Science, April, 1960. The essentials of this computer program are given in Appendix $B$ under the section UNIVAC 1108. 



\section{APPENDIX B \\ Available Computer Programs at NBS for \\ Time Series Analysis}

Several time-sharing interactive systems were immediately available at NBS. These were DIALCOM, Computer Sciences Corporation Conversational Executive and General Electric Mark II. In addition the Large Scale Systems STAT-PACK for the UNIVAC 1108 tests several routines for time series analyses. A summary of the pertinent program libraries of each of these systems follows.

DIALCOM: Moving Average (A Simple Moving average)

Autocovariance

Cross Covariance

Smoothed Series (A weighted moving average)

Seasonal Index and Cyclical Movement

Note: No expontential smoothing method is available and none of the programs have an extrapolation feature.

\section{Computer Sciences Conversational Executive (CSCX}

Basic Library): This has a Triple Exponential Smoothing routine called ***SMOOTH. In addition to smoothing, and listing the smoothed values and differences, the routine can produce a plot of the observed values and the smoothed values (on the same graph) and an extrapolation feature is also available. 
There is no routine available for first or second order smoothing and there is no automatic feature such as a mean absolute deviation. The value of the smoothing constant must be supplied by the user.

\section{General Electric (Mark II): The ExPSMOOTHING}

routine is a very comprehensive routine which performs a sequence of exponential smoothing operations for a number of alpha values for each order of smoothing: 1 , 2, 3. The routine then selects that combination of alpha and order of smoothing that has minimum mean absolute deviation per data point. A forecast (extrapolation) option is also available, along with a plot. A variety of output options is possible.

The routine also permits the users to override several automatic features of the routine. For example, the user has the capability to specify cycle length of known periodic data and also to specify the values of the smoothing constants, but not the order of smoothing. A summary of the essential details of this particular routine is given in Appendix $C$.

\section{UNIVAC 1108: The Large Scale systems STAT-PACK}

for the UNIVAC 1108 lists several routines for time series analysis. These are UNIVAC system subroutines and are not necessarily National Bureau of Standards routines, but they are available for use on the NBS UNIVAC 1108. The most appropriate subroutine for the problem at hand appears to be GEXSMO - Generalized 
Exponential Smoothing.* The routine

1. Produces the seasonally adjusted series point $\tilde{S}_{t}$

2. Computes a seasonality factor $\mathrm{F}_{t}$ to be used in the next cycle

3. Computes the next trend value $R_{t}$

4. Produces a forecast for the next period, ** $\mathrm{S}_{t, 1}$

5. Compares the forecast with the actual to get the forecast error

$$
e_{t, 1}=s_{t+1}-s_{t, 1}
$$

where $s_{t+1}$ is the $(t+1)$ st time series data point.

When all the data are used, I forecasts for future

periods may be produced by using the equation

$$
\mathrm{S}_{\mathrm{N}, \mathrm{K}}=\left(\tilde{\mathrm{S}}_{\mathrm{N}}+\mathrm{KR}_{\mathrm{N}}\right) \mathrm{F}_{\mathrm{N}-\mathrm{L}+\mathrm{K}} \mathrm{K}=1,2, \ldots, \mathrm{L} \underset{\text { increasing) }}{(\text { Linear }}
$$

where $L$ is the periodicity of the data, e.g., if the data

is by month, $L=12$ and $\mathrm{N}$ is the number of elements in

the time series.

Three exponential smoothing factors, A, B, and C

all between 0 and $I$ are used respectively to produce

the seasonally adjusted series, to adjust the seasonality

factors and to adjust the trend. These smoothing factors

and initial values may be input or may be calculated by

the routine.

*The notation used here is that employe? in the UNIVAC Programmers Reference Manual. The mathematical background for the method as given in winters, P.R.: Forecasting Sales by Exponentially Weighted Moving Averages, Management Science, April, 1960.

**In this context "next period" refers to the next time point. 
The output of the GEXSMO routine is listed under the headings:

ORIGINAL SEASONALLY FORECASTED SEASONALITY TREND ERROR SERIES ADJ. SERIES SERIES

and this is followed by

MEAN ABSOLUTE DEVIATION OF FORECAST ERRORS PERCENTAGE ERROR

We mention the availability of other UNIVAC time series routines:

1. MOVAVG - Moving Averages. This subroutine computes the smoothing coefficients in a polynomial model for a time series and smooths the given time series.

2. SEASHI - Shiskin's Seasonality Factors. This subroutine produces seasonality factors from a time series, and smooths, detrends and deseasonalizes the series.

3. WEMAV - Weighted Moving Averages. This subroutine eliminates a trend from a time series by a weighted moving average.

4. TRELS - Trend Analysis by Least Squares. This subroutine removes trends in a time series with a general linear model, using least squares. 
5. VADIME - Variate Difference Method. This subroutine estimates the variance of the random component in a time series and determines a lower limit for the degree of the polynomial which can be used in approximating the trend.

6. TSFARG - Autoregressive Model. This subroutine obtains the least square coefficients in an autoregressive time series model and produces forward forecasts from the model.

The documentation of the detail of each of these seven programs is very adequately done in the UNIVAC Programmer's Reference Manual for STAT-PACK and is not repeated here. 

The EXPSMOO'THING routine is a very comprehensive routine which performs a sequence of exponential smoothing operations for a number of alpha values for each order of smoothing: $1,2,3$. The routine then selects that combination of alpha and order of smoothing that has minimum mean absolute deviation per data point. A forecast (extrapolation) option is also available, along with a plot. A variety of output options is possible. The routine also permits the users to override several automatic features of the routine. For example, the user has the capability to specify cycle length of known periodic data and also to specify the values of the smoothing constants, but not the order of smoothing.

For the convenience of the reader we present a summary of the essentials of the General Electric Time Sharing EXPSMOOTHING Routine. The discussion is based on experience in using the routine and explanations of this routine from two User's Guides* prepared by the

*Mark II User's Guide: Statistical Analysis System, General Electric Company, December, 1971 (5707.01).

GETSA\$: Mark I Marketing and Economic Forecasting, A Hands-On Users Guide, General Electric Company, 1969. (906329) 
the General Electric Company, and is prepared in the sequence provided by the version in use in December, 1972. For additional details on program operation the reader is referred to the user's guides. The time series data to be subject to the EXPSMOOTHING routine is called RAW DATA by the program. The RAW DATA may be adjusted initially by what is called a BASE SERIES. This series permits one to remove known distortions that one would not expect to occur at future times. The base series may be used to take into account discontinuities, human judgment or the results of statistical analyses of the data. The base series values are subtracted from the raw data before an analysis is made and later added back into the forecast.

To operate the program, in addition to entering the raw data and the base series, one has to indicate two times, the LEAD TIME (Is) and the FORECAST HORIZON (H) as well as a choice of six output options. Lead time is the term used to describe the time (in periods) between the last piece of data one has as data as input and the period one is most interested in estimating correctly. The forecast will be optimized according to the lead time that is entered.

The forecast horizon indicates how many periods beyond the last data point will be forecasted, but has 
nothing to do with the optimization. For example, if the raw data is reported monthly and the user wishes to forecast six months in the future, accurately, and also wishes to take a casual glance at the forecast one year ahead, a lead time of six and a horizon time of 12 would be indicated.

The output options are cumulative, so that option code 5 gives all options. The codes for the output options are:

$0=$ Simple forecast table

1 = Raw data residue

2 = Raw data list

3 = Base series list and cyclic analysis

$4=$ Cyclic forecast

5 = Trend and error analysis and composite forecast.

A graphical display of the raw data and forecasted (smoothed) and extrapolated data may also be obtained.

The following discussion is based on maximum output (Code 5). The output indicates whether the smoothing constant was supplied or provided automatically by the programs and
a. NUMBER OF RAW DATA POINTS
b. NUMBER OF BASE DATA POINTS
C. FORECAST HORIZON
d. LEAD TIME.

Next, the RAW DATA are printed out. 
Then comes DETERMINATION OF THE OPTIMUM NUMBER OF DATA POINTS PER CYCLE. The entries are in columns $K$ and ERR(K), where $K$ refers to cycle length as expressed in data periods, and where $K$ runs from 1 to half the number of data points. The ERR(K) shows a measure* of error associated with each cycle length. The GETSA\$ user's guide states:

The lower the error, the stronger is the tendency for the data to conform to a cyclic pattern. The absolute value of the error term has little significance for interpretation, but the relative value shows which cycle length fits best and that length ( $K$ value) is chosen as the optimum length and subsequent calculations assume a cycle of that length.... The optimum number of periods per cycle will be chosen based on minimum error. That cycle length is assumed for the remainder of the analyses.

If $\min E R R(K)$ occurs for $K=1$, the routine will indicate that the data is not cyclic.

Then the output indicates THE OPTIMUM PERIOD FOR THE CYCLE and prints out the corrections that are used to remove the cyclic effects, under the headings $\mathrm{T}$ and $\mathrm{C}(\mathrm{T}) * *$

*We have been unable to determine the exact nature of this measure.

**We have been unable to determine the exact nature of this correction. 
Next there appears TABULATION OF THE ACTUAL

(UNSMOOTHED) RESIDUE. The residue at this stage contains the corrections for base series and cyclic effects. At this point the

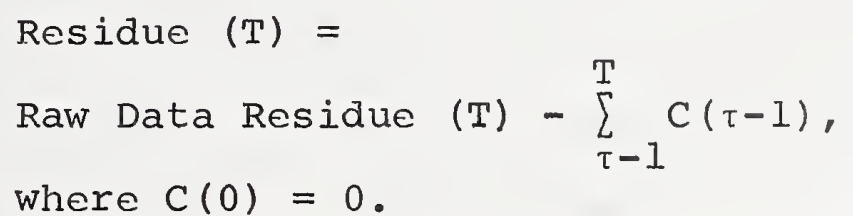

The output then indicates the results of EXPONENTIAL SMOOTHING APPLIED TO RESIDUE: under the headings $\begin{array}{ll}\text { ALPHA TYPE OF SMOOTHING } & \text { MEAN ABSOLUTE } \\ & \text { DEVIATION PER DATA } \\ & \text { POINT }\end{array}$ If the alpha values are not supplied but are determined by the program, the program will select* eight (8) values of alpha and do exponential smoothings of orders 1, 2, and 3 for each alpha. The minimum absolute deviation per data point for this set of 24 smoothings then determines the alpha value and order of smoothing that will be employed in the so-called FORECAST section of the program. The output headings at this stage are:

$\begin{array}{lll}\text { OPTIMUM } & \text { TYPE OF } & \text { MEAN ABSOLUTE DEVIATION } \\ \text { ALPHA } & \text { SMOOTHING } & \text { PER DATA POINT }\end{array}$

followed by

TIME RESIDUE COMPOSITE ACTUAL ERROR

*If a is not forced, program will select 8 values of $\alpha$ based on $\alpha=\frac{1}{8} \frac{2}{\mathrm{~L}+1}$. The leading term is always $\alpha_{1}=.01$. The second term is $\alpha_{2}=\min (.05, \alpha)$. If $\alpha_{2}=.05, \alpha_{3}=\alpha_{,} \alpha_{4}=2 \alpha, \ldots, \alpha_{8}=6 \alpha$. If $\alpha_{2}=\alpha, \alpha_{3}=2 \alpha, \alpha_{4}=3, \ldots, \alpha_{8}=7 \alpha$. 
Under TIME the initial entry is at time $5+\mathrm{L}$, where $\mathrm{L}$ is the lead time. Several observations are required before a smoothed average can be calculated and this routine uses five.

The RESIDUE indicated is the smoothed residue. Under COMPOSITE appear the results of putting back in the reverse corrections for cyclic effects and base series.

Under ACTUAL are listed the values that were originally listed as RAW DATA.

Under ERROR appear the results of ACTUAL minus COMPOSITE. The entries under RESIDUE and COMPOSITE beyond the last ACTUAL data point are based on the exponential smoothing forecast formulas* of orders $1,2,3:$

$$
\begin{aligned}
& F 1_{t+L}=S I_{t}=\operatorname{CED} 1_{t} \\
& F 2_{t+L}=C E D 2_{t}+L\left(C 2_{t}\right) \\
& F 3_{t+L}=C E D 3_{t}+L\left(C 3_{t}\right)+1 / 2 L^{2}\left(R C 3_{t}\right)
\end{aligned}
$$

The values that are actually used in the extrapolation are listed under the headings:

SI

CEDI

$\mathrm{C} 2$
S2

CED2

C 3

\section{S3}

CED 3

$\mathrm{RC} 3$

The values shown are for the last raw data point.

*These and other formulas used in the exponential smoothing, process can readily be transformed into the notation used in Brown's book in pages 142-144 and pages $184 \mathrm{ff}$. 
This is followed by HORIZON FORECAST BEGINS AT TIME and LEAST SQUARES FIT

and MEAN and VARIANCE.

The LEAST SQUARES FIT is simply an equation describing the straight line trend which best approximates (in the sense of least squares) movement of the raw data for all the data.

At this time the computer will ask WANT A PLOT? and WANT DATA STORED? If a plot is desired, this routine will give on one graph plots of the values listed under FORECAST COMPOSITE and ACTUAL. 

FORM NBS-114A 11.711

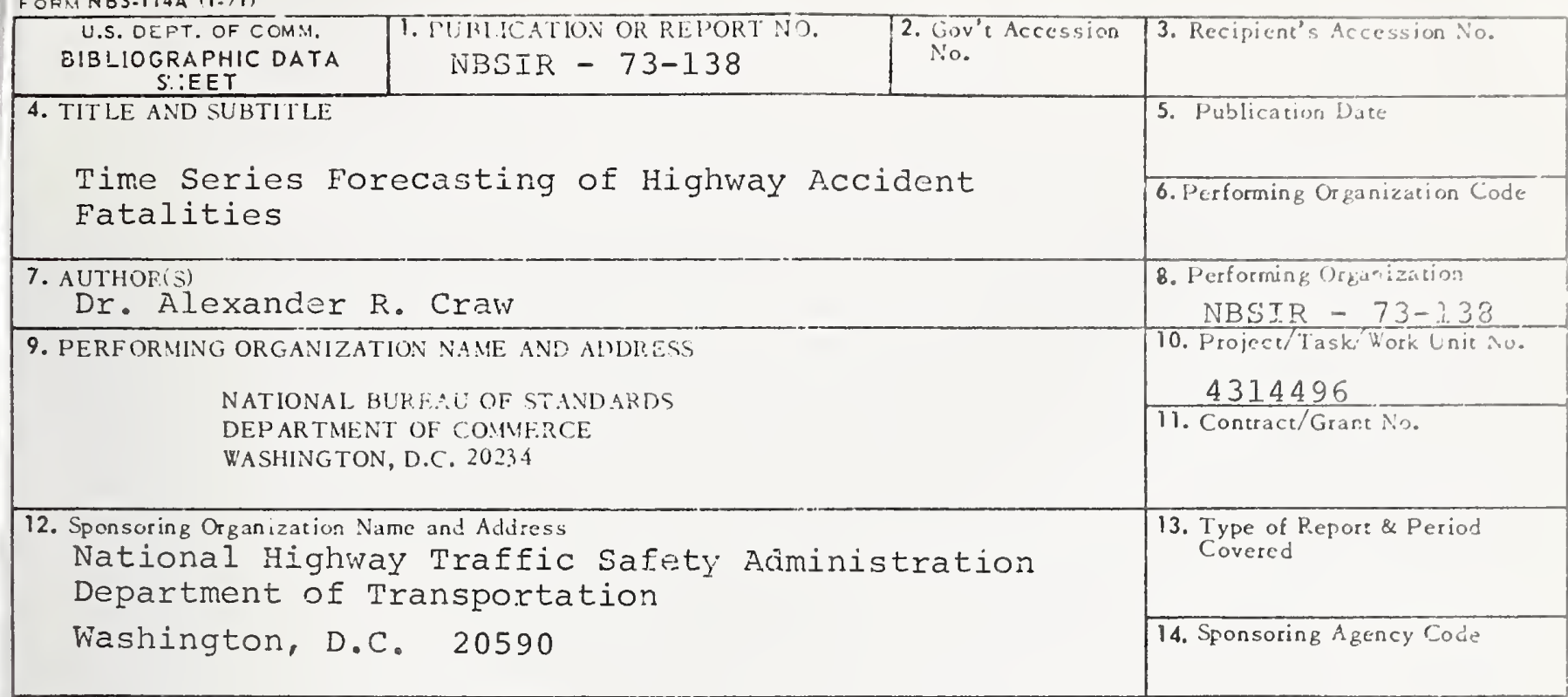

15. SUPFLEMENTARY NOTES

16. ABSTRACT (A 200-word or less factual summary of most significant information. If document tacludes a significant bibliography or literature survey, mention it here.)

Using twelve years of time series data on highway fatalities, the methodology currently employed by the National Highway Trafic bafety Administration (NHTSA) to forecast the annual (calendar year) total of highway accident fatalities were compared with those bbtained by several computer routines based on exponential smoothing techniques and available at the National Bureau of Standards. The use of unadjusted and seasonally adjusted data was also examined.

It is found that there is no coercive evidence to lead to abandoning the present NHTSA methods in favor of readily available compute routines based on exponential smoothing methods.

of the methods examined in this study, the best results were

bbtained with the EXPSMOOTHING routine using unadjusted fatality data.

17. KEY WORDS (Alphabetical or jer, separated by semicolons)

Exponential smoothing; fatalities; highway accidents; time series

18. AVAILABILITY STATEMENT

X] UNL IMITED.

FOR OFFICIAL DISTRIBUTION. DO NOT RELEASE TO NTIS.

\begin{tabular}{|c|c|}
\hline $\begin{array}{l}\text { 19. SECURIYY CLASS } \\
\text { (THIS REPORT) } \\
\text { UNCL_ASSIFIED }\end{array}$ & 21. NO. OF PAGES \\
\hline $\begin{array}{l}\text { 20. SECURITY CLASS } \\
\text { (THIS PAGE) }\end{array}$ & 22. Price \\
\hline
\end{tabular}




